Research Article

\title{
Evaluation of Waterlogging Risk in an Urban Subway Station
}

\author{
Haiying Yu $\mathbb{D},{ }^{1,2}$ Chuan Liang $\mathbb{D},{ }^{1}$ Ping Li, ${ }^{3}$ Kaijie Niu, ${ }^{1}$ Faxing Du, ${ }^{4}$ Junhu Shao, ${ }^{2}$ \\ and Yuyong Liu $^{5}$ \\ ${ }^{1}$ Sichuan University, Chengdu, China \\ ${ }^{2}$ Sichuan Normal University, Chengdu, China \\ ${ }^{3}$ Tsinghua University, Beijing, China \\ ${ }^{4}$ China Three Gorges University, Yichang, China \\ ${ }^{5}$ China Railway Southwest Research Institute Co., LTD, Chengdu, China \\ Correspondence should be addressed to Haiying Yu; 11756330@qq.com
}

Received 14 May 2019; Revised 21 August 2019; Accepted 6 September 2019; Published 7 October 2019

Academic Editor: Yinshan Tang

Copyright (c) 2019 Haiying Yu et al. This is an open access article distributed under the Creative Commons Attribution License, which permits unrestricted use, distribution, and reproduction in any medium, provided the original work is properly cited.

\begin{abstract}
Most cities in the world have extensive underground facilities, including public transport and commercial facilities, such as shopping malls, subways, and parks. Safety of underground space has been an important aspect of urban safety. Due to the influences of global climate change and human activities, waterlogging disasters in cities are becoming increasingly serious and underground facilities easily suffer from waterlogging disasters. Moreover, waterlogging disasters in cities can cause different degrees of damage to construction period and operating period of urban subway stations. By using the optimal combination weighting method combining subjective and objective weighting, this study assigned weights to evaluation factors. Based on this, a fuzzy synthetic evaluation model for waterlogging risk in the construction and operating periods of urban subway stations was established. Furthermore, the model was applied and verified to be effective in Chengdu Metro Line 4, Sichuan province, China, and the evaluation results coincided with the actual situation. The model in the study provides a new idea for evaluating waterlogging risks in urban subway stations, and these results can offer important information for local government to strengthen management on waterlogging risks.
\end{abstract}

\section{Introduction}

In recent years, due to urbanization effect, climate warming, and sea-level rise, meteorological and hydrological disasters, such as typhoon, rainstorm, and extreme rainfall, frequently occur, which exerts great adverse impacts on construction and operation of urban subways. Accidents caused by floods in urban underground rail transit are also frequently reported. For example, in October 1996, heavy rainfall in Boston, USA, flooded the subway system between Kenmore Square and Hynes Convention Center so that Kenmore square was flooded with water of $5.3 \times 10^{4} \mathrm{~m}^{3}$ at a depth of more than $7 \mathrm{~m}$ [1]. In July, 2001, Seoul in South Korea was hit by an extraordinary rainstorm, flooding the subways, which caused forty-nine deaths, including 21 deaths from electrocution. Moreover, on September 6, 2001, rainstorm and flood induced by Typhoon Nari flooded 18 subway stations in Taipei, China. Together with water accumulated in running tunnels, the total volume of accumulated water was about $3 \times 10^{5}$ t so that the subway system was paralyzed, which brought profound lessons. On April 1, 2004, in the construction site of Lijiao Station of Guangzhou Metro Line 3 in China, the enclosure structure of underground continuous walls suddenly collapsed due to continuous heavy rain. A building only $30 \mathrm{~m}$ from the construction site leaned to the south for $60^{\circ}$, and the foundation pit by the side of the building collapsed, forming a hollow place with the area of more than $1,000 \mathrm{~m}^{2}$, which caused great losses. From June 30 to July 6, 2016, weekly rainfall in Wuhan (Hubei province, China) hit a record high, and heavy rain flooded 206 places in urban areas and forced to shut down three subway stations [2]. The subway stations became flood discharge areas.

For the underlying reason, urban flooding is the result of urbanization. Owing to the fact that many rivers are reduced 
in size with city development, water level rises even though rainfall is same. The constant increase of impermeable area in cities relatively reduces time for flood reaching the downstream cities and results in quicker flooding. Under the circumstances, if there is heavy rain for a long time, drainage network in most cities cannot discharge the flood in time, so urban underground rail transit has potential hazards of being flooded by accumulation of rainstorm water. Groundwater can also seep into engineering linings surrounded by saturated soil for a long time even if the inlet is not flooded. In serious cases, the structure is damaged and ground subsidence happens, which affects the safety of surface buildings in the vicinity [3]. Moreover, most serious collapse accidents tend to happen in underground rail transit projects in the construction period, resulting in serious casualties, property loss, and unpredictable indirect loss. Therefore, evaluation of waterlogging risk and drainage in design phase, construction period, and operating period of urban subways is particularly important.

Although previous studies have made some achievements, there are still some deficiencies in the risk evaluation of urban subways [4-8]. The indexes of risk evaluation are determined qualitatively or based on semiquantitative experience. In fact, qualitative evaluation can effectively guide quantitative evaluation, and the latter can make the former more accurate. Therefore, waterlogging prevention in urban subways was used as research object. Based on this, a risk evaluation method based on optimal combination weighting of analytic hierarchy process (AHP) and entropy evaluation method and the fuzzy synthetic evaluation model was proposed by referring to risk evaluation methods in other fields, such as economics, aviation, and geology $[9,10]$. Furthermore, the method was verified to be feasible and effective by applying it in Chengdu Metro Line 4, thus improving the current situations that the traditional methods cannot be effectively utilized in engineering practices.

\section{Materials and Methods}

According to the procedures, i.e., risk identification, risk assessment, risk evaluation, and risk countermeasures, the risk research was carried out following the above steps, along with case verification [11].

2.1. Risk Identification. Risk identification is the first step of risk evaluation. Through certain methods, the step reveals influences of various uncertain factors on the whole system, and the identified influence factors should be able to comprehensively reflect all characteristics in the current situation of waterlogging prevention in urban subways. These characteristics should not only show engineering factors, such as safety and reliability that are concerned in terms of waterlogging prevention, but also reflect nonengineering factors, such as supposed effects on surrounding buildings, transportation, and human society after waterlogging disasters occur. In view of the presence of many factors influencing safety of preventing flood and draining waterlogging in the subways, this study determined risk factors for preventing flood and draining waterlogging in the urban subways through methods, including investigation, consultation, discussion, negotiation, and reference to other literatures. In addition, main factors affecting flood and waterlogging prevention in the urban subway were analyzed and summarized, and secondary factors with slight influences were eliminated. In this way, the list of influence factors for risk evaluation of the urban subway was formed, as shown in Table 1 $[12,13]$.

2.2. Risk Assessment. After determining the factors influencing waterlogging risks, it needs to assess influence degrees of each factor. At present, scholars in the world have conducted a few research studies on evaluation of waterlogging risk. By referring to the existing research results in other fields, risk assessment methods mainly include AHP, matter-element model, and evidence theory [14-19]. The reliability and correctness of the evaluation results obtained through all methods are directly related to whether factor weights can be scientifically and reasonably determined, while most methods adopt the single subjective or objective weighting method in determining weights of evaluation indexes. The subjective weighting method is mainly based on the knowledge and experience of estimators for judgment, so it can make full use of the knowledge, experience, and prediction ability of risk estimators, but it is subjective and cannot make accurate judgment. These kinds of methods mainly include the AHP, line-relative method, and Delphi method. The objective weighting methods mainly refer to the method of determining corresponding index weights through mathematical methods by fully exploring the information contained in the original data of attributes. The estimated value is not affected by subjective factors, while sometimes the weight value is not consistent with the reality. The methods include the entropy evaluation method, principal component analysis, and gray correlation method. Therefore, the two types of methods for determining weights of assessment indexes have their own limitations.

This study attempted to estimate weights by using the optimal combination weighting method based on the subjective AHP and objective entropy weight method. The optimal combination weighting method is a method that fully uses objective information of indexes to determine weights of evaluation indexes based on the subjective opinions of estimators. By combining the subjective weighting method with objective one, it takes preferences of decision makers to attributes into account and reduces subjectivity of subjective weighting. In this way, unification of objectivity and subjectivity is reached when determining weights, thus reducing errors between the determined weight and the possible weight of the indexes so that evaluation results are more realistic and reasonable.

2.2.1. Analytic Hierarchy Process (AHP). AHP, which was firstly proposed by Professor Saaty in 1973, a famous 
TABLE 1: List of influence factors for evaluation of waterlogging risk in the urban subway station.

\begin{tabular}{lll}
\hline No. & Influence factor & Description \\
\hline $\begin{array}{ll}\text { Surrounding terrain } & \text { (1) The factor of surrounding terrain of a station } \\
& \text { determines the direction of confluence and flow rate } \\
\text { of rainwater, which may be the prerequisite for } \\
\text { waterlogging. } \\
\text { (2) It has effects in the construction and operation } \\
\text { periods. }\end{array}$ \\
\hline
\end{tabular}

(1) The foundation pit of the subway station is unconnected with the surrounding rivers in the construction period, and rivers or other large ditches for draining flood are found in the surrounding of the subway station. On the whole, it can be regarded as a

$u_{2} \quad$ River course favorable factor for preventing waterlogging.

(2) Internal drainage system has been connected to external municipal pipe network and rivers in the operating period of the station and is not isolated any more. For too high water level of rivers, the backward flow of water should be taken into account, which can exert adverse impacts.

(1) Standard, scale, and construction degree of drainage pipe network within a certain range around the subway station have important influences on waterlogging prevention in the subway station.

(2) The location of the drainage pumping stations in the station relative to surrounding rainwater pipe networks or the mouth of a river should be considered. On extreme weather conditions, excessive rainwater accumulated in rainwater pipes can lead to water flowing backward, which exerts adverse effects.

(1) Municipal sewage and feed-water main pipes are extremely likely to burst in the construction period, and water in the pipes overflows after bursting of the pipes. Under the effects of pressured water flowing, soil layer of the wall of the foundation pit becomes unstable, collapsing foundation pit, which causes serious consequences.

$u_{4} \quad$ Municipal sewage and feed-water main pipes

(2) By comprehensively considering accidental factors and the above reasons, municipal sewage and feed-water main pipes in the construction period are considered to be an adverse factor, which has great influences and hazards on the construction period. However, the probability of pipe bursting is greatly reduced in the operating period, so it has slight effects.

(1) During the construction period, wall of the foundation pit plays a temporary role in seepage control and support and has a simple structure, so influence of hydrogeology is quite significant.

$u_{5} \quad$ Hydrogeological condition

(2) During the operating period, because a reliable structural antiseepage system has been formed in the station, the impacts of groundwater are basically eliminated and hydrogeological condition has little effect. 
TABLE 1: Continued.

\begin{tabular}{|c|c|c|}
\hline No. & Influence factor & Description \\
\hline$u_{6}$ & Regional situation & $\begin{array}{l}\text { (1) During the construction period, it is necessary to } \\
\text { encircle the construction site and control the traffic } \\
\text { around the construction site, which aggravates the } \\
\text { original traffic and pedestrian flow and affects the } \\
\text { surrounding important public facilities. Therefore, in } \\
\text { comparison with the operating period, it has greater } \\
\text { influences in the construction period. } \\
\text { (2) Regional situation, such as the distance from the } \\
\text { station to densely populated area, complete and } \\
\text { smooth road networks around the station, and } \\
\text { smooth allocation of emergency supplies can affect } \\
\text { short-term and long-term planning for waterlogging } \\
\text { prevention in the urban subway stations. }\end{array}$ \\
\hline
\end{tabular}

mathematician in the United States, is a method combining qualitative weighting and quantitative weighting of risk factors [20]. Being a multicriteria decision-making method, AHP helps solving complex problems with multiple conflicting and subjective criteria, such as projects ranking and location or investment selection [21]. The basic idea of AHP is to decompose a complex problem into different levels and factors and construct judgment matrix by comparing the importance of each hierarchy and factor. Moreover, the maximum eigenvalue $\lambda_{\max }$ and corresponding eigenvector $W$ are obtained through matrix calculation. After normalization processing, weights of each hierarchy of indexes can be obtained. The specific steps are shown as follows.

(1) Establishing the Structure Model of AHP. In general, the structural model of AHP is divided into three hierarchies. The top hierarchy is the intended objective to be reached through systematical analysis; the middle hierarchy includes some criteria and subcriteria involved in realizing the general objective on the top hierarchy. Moreover, the bottom hierarchy consists of various measures, decisions, and schemes selected for achieving the objective.

(2) Constructing Judgment Matrix. The relative importance of $n$ evaluation factors is judged, and the judgment is quantified through 1 9 scaling method. The meaning of the scaling method is demonstrated in Table 2 [22]. After that, the judgment matrix $A$ with dimension of $n \times n$ is built through pairwise comparison, as shown in the following formula:

$$
A=\left[\begin{array}{ccc}
a_{11} a_{12} & \cdots & a_{1 n} \\
a_{21} & a_{22} \cdots & a_{2 n} \\
\vdots & \vdots & \vdots \\
a_{n 1} & a_{n 2} \cdots & a_{n n}
\end{array}\right]=\left(a_{i j}\right)_{n \times n}
$$

TABLE 2: 1 9 scaling method.

\begin{tabular}{|c|c|}
\hline $\begin{array}{l}\text { Scale of importance } \\
a_{i j}\end{array}$ & Definition \\
\hline 1 & Factors $i$ and $j$ are equally important \\
\hline 3 & $\begin{array}{l}\text { Factor } i \text { is slightly more important than } \\
\text { factor } j\end{array}$ \\
\hline 5 & Factor $i$ is more important than factor $j$ \\
\hline 7 & Factor $i$ is much more important than factor \\
\hline 9 & $\begin{array}{l}\text { Factor } i \text { is absolutely more important than } \\
\text { factor } j\end{array}$ \\
\hline $2,4,6,8$ & $\begin{array}{l}\text { The scale values corresponding to the } \\
\text { intermediate states between the above } \\
\text { adjacent judgments }\end{array}$ \\
\hline $1 / a_{i j}($ reciprocal $)$ & $\begin{array}{l}\text { Judged value is obtained by comparing } \\
\text { factor } j \text { with factor } i\end{array}$ \\
\hline & $a_{i i}=1$ \\
\hline & $a_{i j}=\frac{1}{a_{j i}}$ \\
\hline & $a_{i j}=\frac{a_{j k}}{a_{i k}}$ \\
\hline
\end{tabular}

(3) Calculating the Maximum Eigenvalue $\lambda_{\max }$ and Weight Vector $W$. The weight vector is calculated by using the arithmetic mean method:

$$
\begin{aligned}
w_{i} & =\frac{1}{n} \sum_{j=1}^{n} \frac{a_{i j}}{w_{i} \sum_{k=1}^{n} a_{k i}}, \\
\lambda_{\max } & =\sum_{i=1}^{n} \frac{(A W)_{i}}{n w_{i}},
\end{aligned}
$$

where $\lambda_{\max }$ and $w_{i}$ represent the maximum eigenvalue of the 
judgment matrix $A$ and the weight vector corresponding to $\lambda_{\max }$, respectively; $i, j=1,2, \ldots, n$; and $n$ indicates the number of evaluation factors.

(4) Consistency Check. Due to complexity of objective things and fuzzy judgment and comparison of things of human, $a_{i j}$ in the above judgment matrix is likely to have deviation with the actual ratio. Therefore, it is necessary to carry out consistency check on the weights obtained through judgment matrix, and the values that pass the consistency test are reliable. The test method is shown as follows:

(1) Calculating consistency index CI:

$$
\mathrm{CI}=\frac{\lambda_{\max }-n}{n-1}
$$

(2) Calculating random consistency rate CR:

$$
\mathrm{CR}=\frac{\mathrm{CI}}{\mathrm{RI}}
$$

where RI indicates the random consistency index and can be obtained in Table 3 [23].

(3) Judgment:

If $\mathrm{CI}=0$, it means complete consistency and the weights obtained through judgment matrix are completely reliable.

If $\mathrm{CI} \neq 0$, it needs to further test CR. If $\mathrm{CR}<0.1$, the consistency of the matrix is generally accepted and the influence weights of the factors determined by the judgment matrix on the objective are set reasonably. If $\mathrm{CR} \geq 0.1$, it is generally considered that consistency of the matrix is unacceptable and the judgment matrix needs to be constructed until consistency meets the requirements.

(5) Total Ranking of Each Hierarchy and Consistency Check

(1) Total ranking of levels:

Total ranking of levels is to calculate total weights of each level, that is, to assign a weight to the importance of all factors at a given level relative to those at the highest level. It needs to be carried out and synthesized from top to bottom layer by layer. The steps are presented as follows.

It is assumed that the weight vector of $m$ elements in the $k-1$ th level in relative to the total objective is

$$
w^{(k-1)}=\left(w_{1}^{(k-1)}, w_{2}^{(k-1)}, \ldots, w_{m}^{(k-1)}\right)^{T} .
$$

It is supposed that the weight vector of single ranking of $n$ elements in the $k$ th hierarchy in relative to the $j$ th element in the upper hierarchy (the $k-1$ th hierarchy) is
TABle 3: The random consistency index RI under different dimensions.

\begin{tabular}{lcccccccccc}
\hline $\begin{array}{l}\text { Matrix } \\
\text { dimension }\end{array}$ & 1 & 2 & 3 & 4 & 5 & 6 & 7 & 8 & 9 & 10 \\
RI & 0 & 0 & 0.58 & 0.90 & 1.12 & 1.24 & 1.32 & 1.41 & 1.45 & 1.49 \\
\hline
\end{tabular}

$p_{j}^{(k)}=\left(p_{1 j}^{(k)}, p_{2 j}^{(k)}, \ldots, p_{n j}^{(k)}\right)^{T}, \quad j=1,2, \ldots, m$

Weight of the elements that are not subjected to control of $j$ is $0 . p^{(k)}=\left(p_{1}^{(k)}, p_{2}^{(k)}, \ldots, p_{n}^{(k)}\right)$ represents the ordering of element in the $k-1$ th hierarchy by elements in the $k$ th hierarchy, so the total ranking of the elements in the $k$ th hierarchy to the total objective is obtained as follows:

$$
\begin{aligned}
w^{(k)} & =\left(w_{1}^{(k)}, w_{2}^{(k)}, \ldots, w_{n}^{(k)}\right)^{T}=p^{(k)} w^{(k-1)}, \\
\text { or } w_{i}^{(k)} & =\sum_{j=1}^{m} p_{i j}^{(k)} w_{j}^{(k-1)}, \quad i=1,2, \ldots, n .
\end{aligned}
$$

(2) Consistency check on the total ranking results:

Assuming that $\mathrm{CI}_{j}^{(k)}, \mathrm{RI}_{j}^{(k)}$ and $\mathrm{CR}_{j}^{(k)}, j=1,2, \ldots$, $m$ has been calculated by using the $j$ th element in the $k-1$ th hierarchy as criterion, the comprehensive test index of the $k$ th hierarchy is

$$
\begin{aligned}
\mathrm{CI}_{j}^{(k)} & =\left(\mathrm{CI}_{1}^{(k)}, \mathrm{CI}_{2}^{(k)}, \ldots, \mathrm{CI}_{m}^{(k)}\right) w^{(k-1)}, \\
\mathrm{RI}_{j}^{(k)} & =\left(\mathrm{RI}_{1}^{(k)}, \mathrm{RI}_{2}^{(k)}, \ldots, \mathrm{RI}_{m}^{(k)}\right) w^{(k-1)}, \\
\mathrm{CR}^{(k)} & =\frac{\mathrm{CI}^{(k)}}{\mathrm{RI}^{(k)}}
\end{aligned}
$$

The consistency check is conducted hierarchy by hierarchy. When the consistency rate of the $k$ th hierarchy $\mathrm{CR}^{k}<0.10$, it is considered that the satisfactory consistency of recursion order hierarchy is shown in the $k$ th hierarchy.

2.2.2. Entropy Evaluation Method. In the theory of information, information entropy is a method to measure uncertainty and reflects disorder degree of information. In the formula, the smaller the information entropy, the smaller the disorder degree of a system and the larger the utility value of information; otherwise, contrary results are obtained.

Entropy evaluation method can objectively reveal disorder of information of data. It determines weight of indexes based on the judgment matrix constructed by values of evaluation indexes, which can eliminate subjectivity of each factor weight as far as possible so that evaluation results are practical. The calculation steps are as follows [24, 25].

(1) Constructing the judgment matrix $R$ of $m$ evaluation indexes in $n$ schemes: 


$$
R=\left(x_{i j}\right)_{n m}, \quad i=1,2, \ldots, n ; j=1,2, \ldots, m .
$$

(2) Normalizing judgment matrix to obtain the normalized judgment matrix $B$ :

$$
b_{i j}=\frac{x_{i j}-x_{\min }}{x_{\max }-x_{\min }},
$$

where $x_{\max }$ and $x_{\min }$ indicate the most or least satisfied results in different schemes under the same index (the smaller or larger the index is, the more satisfied the obtained results are).

(3) According to definition of entropy, for $m$ evaluation indexes in $n$ schemes, the entropy of the evaluation indexes can be determined as follows:

$$
\begin{aligned}
& H_{j}=-\frac{1}{\ln n}\left(\sum_{i=1}^{n} f_{i j} \ln f_{i j}\right), \\
& \quad i=1,2, \ldots, n ; j=1,2, \ldots, m,
\end{aligned}
$$

$$
f_{i j}=\frac{b_{i j}}{\sum_{i=1}^{n} b_{i j}} .
$$

In order to make $\ln f_{i j}$ meaningful, it is generally assumed that $f_{i j} \ln f_{i j}=0$ when $f_{i j}=0$. However, when $f_{i j}=1, \ln f_{i j}$ is also equal to zero, which is obviously inconsistent with the reality and contradicts with the meaning of entropy. Therefore, $f_{i j}$ needs to be corrected and defined as

$$
f_{i j}=\frac{1+b_{i j}}{\sum_{i=1}^{n}\left(1+b_{i j}\right)} .
$$

(4) Calculating entropy weight $W$ of evaluation indexes:

$$
\begin{aligned}
\omega_{j} & =\frac{1-H_{j}}{m-\sum_{j=1}^{m} H_{j}}, \\
W & =\left(\omega_{j}\right)_{1 \times m}, \\
\sum_{j=1}^{m} \omega_{j} & =1 .
\end{aligned}
$$

2.2.3. Optimal Combination Weighting Method. The weights of evaluation indexes of waterlogging risk were finally determined by using the optimal combination weighting method. The weights determined based on the above steps combine the subjective weighting method with objective one so that the determined weight coefficient can simultaneously reflect subjective and objective information. The specific formula is shown as follows:

$$
w_{j}=a w_{j_{\text {subjective }}}+b w_{j_{\text {objective }}},
$$

where $W_{j_{\text {subjective }}}$ and $W_{j_{\text {objective }}}$ separately represent the subjective and objective weights; $a$ and $b$ are corresponding undetermined coefficients, respectively; and $w_{j}$ denotes the combination weight. It is obvious that the key to determining the combination weight is to determine the undetermined coefficient. According to references, the following formulas are used for calculation [26]:

$$
\begin{aligned}
& a_{1}=\frac{\sum_{i=1}^{n} \sum_{j=1}^{m} w_{j_{\text {subjective }}} x_{i j}}{\sqrt{\left(\sum_{i=1}^{n} \sum_{j=1}^{m} w_{j_{\text {subjective }}} x_{i j}\right)^{2}+\left(\sum_{i=1}^{n} \sum_{j=1}^{m} w_{j_{\text {objective }}} x_{i j}\right)^{2}}}, \\
& b_{1}=\frac{\sum_{i=1}^{n} \sum_{j=1}^{m} w_{j_{\text {objective }}} x_{i j}}{\sqrt{\left(\sum_{i=1}^{n} \sum_{j=1}^{m} w_{j_{\text {subjective }}} x_{i j}\right)^{2}+\left(\sum_{i=1}^{n} \sum_{j=1}^{m} w_{j_{\text {objective }}} x_{i j}\right)^{2}}} .
\end{aligned}
$$

In order to meet normalization conditions, $a_{1}$ and $b_{1}$ are substituted into formulas (20) and (21) for normalization processing and $a$ and $b$ are finally obtained and substituted into formula (17), thus obtaining the combination weight.

$$
\begin{aligned}
& a=\frac{a_{1}}{a_{1}+b_{1}}, \\
& b=\frac{b_{1}}{a_{1}+b_{1}} .
\end{aligned}
$$

2.3. Fuzzy Evaluation Model. Based on the determination of weights of evaluation factors by using the optimal combination weighting method, it is considered that safety of waterlogging prevention of the urban subway in the construction and operating periods is affected by many factors. However, some of these factors are certain and some are uncertain. Moreover, some factors are difficult to be measured and index values are hard to be ascertained accurately. Therefore, safety risks of waterlogging prevention of the urban subway are quantitatively evaluated by combining the optimal combination weighting method with the risk evaluation model with fuzzy attributes. The purpose is to make evaluation results more accurate and scientific and provide references for early warning, prevention, and control of waterlogging disasters in the urban subway. The fuzzy comprehensive evaluation method mainly aims at the evaluation system whose index values are difficult to be ascertained accurately [27]. The specific modeling steps are shown in the following sections.

\subsubsection{Determining Evaluation Factor Set $U$ and Judgment Set} $V$. The evaluation index set $U=\left\{u_{1}, u_{2}, \ldots, u_{i}\right\}$ is defined according to the specific evaluation system, where $u_{i}$ represents the index of the evaluation system. In risk analysis of waterlogging prevention, it is defined that $U=$ \{terrain, river, groundwater ... ( $i$ indicates the number of indexes). 
Possible judgment set of factors is $V=\left\{v_{1}, v_{2}, \ldots, v_{j}\right\} . v_{j}$ and $j$ denote the level of risks and the number of evaluation levels, respectively.

2.3.2. Determining Membership Function. The determination of membership function can quantitatively describe fuzzy concepts, so it is a key step of fuzzy evaluation. The specific modeling formula refers to the experience of relevant scholars, and the normal membership function is utilized [28].

$$
\begin{aligned}
r_{i j} & =e^{-((x-m) / c)^{2}}, \\
m & =\frac{1}{2}\left(x_{i}+x_{i+1}\right), \\
c & =0.6\left(x_{i+1}-x_{i}\right),
\end{aligned}
$$

where $x$ indicates the actual value and $x_{i}$ and $x_{i+1}$ separately represent the upper and lower limits of an evaluation factor corresponding to a certain risk level.

2.3.3. Establishing Fuzzy Evaluation Matrix. Fuzzy evaluation matrix $R$ shows the mapping from the evaluation factor set $U$ to the judgment set $V . r_{i j}$ represents the actual value of the $i$ th factor to the $j$ th rating grade in the evaluation system and can be obtained through formula (22):

$$
R=\left(r_{i j}\right)_{n \times s}, \quad i=1,2, \ldots, n ; j=1,2, \ldots, s .
$$

2.3.4. Fuzzy Comprehensive Evaluation. Through fuzzy evaluation and calculation on weight index set $W$ and fuzzy evaluation matrix $R$ obtained through the combination weighting method, fuzzy evaluation vector $B$ can be obtained, as shown in the following formula:

$$
B=W \times R=\left(w_{1}, w_{2}, \ldots, w_{n}\right) \times\left(r_{i j}\right)_{n \times s}=\left(b_{1}, b_{2}, \ldots, b_{s}\right) .
$$

Based on the calculated fuzzy evaluation vector $B$, the maximum value of the corresponding grade of membership and the risk judgment level can be judged, thus determining grades of fuzzy comprehensive evaluation on flood prevention in the urban subway station. In other words, based on grade of membership $b_{r}=\max \left\{b_{j}\right\}(1 \leq j \leq s)$, the grades of risk levels can be determined.

\section{Case Study of the Model to Wenjiachang Metro Depot in Phase I of Chengdu Metro Line 4}

3.1. Analysis of General Situation of the Researched Region. By taking Wenjiachang Metro Depot in phase I of Chengdu Metro Line 4 as an example, the evaluation of flood risk in the subway was studied by using the established model. For the engineering line in phase I of Chengdu Metro Line 4 with the overall length of about $22.4 \mathrm{~km}$, there are 16 stations in total, with average interval of about $1.32 \mathrm{~km}$. All belong to underground lines and stations. The total investment is estimated to be $1.2562 \times 10^{10}$ yuan. There is a metro depot, namely, Wenjiachang Metro Depot in the phase I project of the line 4 and two main transformer substations.

Wenjiachang Metro Depot, basically located within Lvzhou Park in Chengdu city, Qingyang district, has a large area of grassland and woods as well as densely distributed houses for residents (peasants). Planting soil that is plastic in local areas is mainly found on the surface in the field, and local areas are low lying and wet. In particular, for Supo branch canal and its influence scope, due to long-term immersion, clayey soil is mainly soft plastic to plastic, and some belong to soft to loose and soft soil, showing large porosity ratio and high water content and compressibility. Characteristic measured area with poor mechanical properties is located in the I-level terrace of Minjiang river system, on which it is clayey soil with the thickness of $2 \sim 4 \mathrm{~m}$ of Quaternary Holocene alluvial deposit $\left(Q_{4}{ }^{a l}\right)$, and the soil is mainly hard plastic, with plastic soil in local areas. Planting soil is mainly distributed at the surface of $1 \mathrm{~m}$ thick, and filling soil is seen in local areas. Below the surface, slightly dense to moderately dense lenticular sand layers sandwiched with boulder and pebble soil with a large particle size are mainly distributed, and the thickness is $7 \sim 11.8 \mathrm{~m}$. The upper Pleistocene series $\left(Q_{3}{ }^{\text {fgl+al }}\right)$ containing boulder and pebble soil with a large particle size lies in the deeper layers, and the exposed part shows the thickness of $5.5 \sim 11.8 \mathrm{~m}$, and thin layers of lenticular sand with the thickness of about $0.4 \mathrm{~m}$ are found in local areas. In addition, ground surface of the metro depot is located in a plain area where there is no municipal drainage system at present, so rain drainage and flood discharge mainly rely on Supo branch canal.

\subsection{Determination of Factor Set and Evaluation Set}

3.2.1. Evaluation Factor Set. In analysis of waterlogging risk in the subway station, because of different influence degrees of some factors in the construction and operating periods, weight coefficients of each corresponding factor are distinct in the construction and operating periods. In this evaluation, six factors, i.e., terrain $u_{1}$, river $u_{2}$, rain facilities $u_{3}$, feedwater pipe $u_{4}$, groundwater $u_{5}$, and regional importance $u_{6}$, were mainly selected for analysis in the construction period. A reliable structural seepage-proofing system has been formed in the station during the operating period, so influences of groundwater are basically eliminated. For the above reasons, the five factors, i.e., terrain $u_{1}$, river $u_{2}$, rain facilities $u_{3}$, feed-water pipe $u_{4}$, and regional importance $u_{6}$, are used for analysis and evaluation during the operating period. Therefore, evaluation factor sets separately are $U=$ $\left\{u_{1}, u_{2}, u_{3}, u_{4}, u_{5}, u_{6}\right\}$ and $U=\left\{u_{1}, u_{2}, u_{3}, u_{4}, u_{6}\right\}$ in the construction and operating periods.

3.2.2. Establishment of Evaluation Set. The evaluation criteria for each factor are shown in Table 4. According to explanations of each factor in the table, each evaluation grade of each factor is specifically quantified. The quantifying idea is that 0 or 1 is taken in ultimate case under the most unfavorable conditions. Of them, the larger the 
TABLE 4: Description of judgment criteria for each factor.

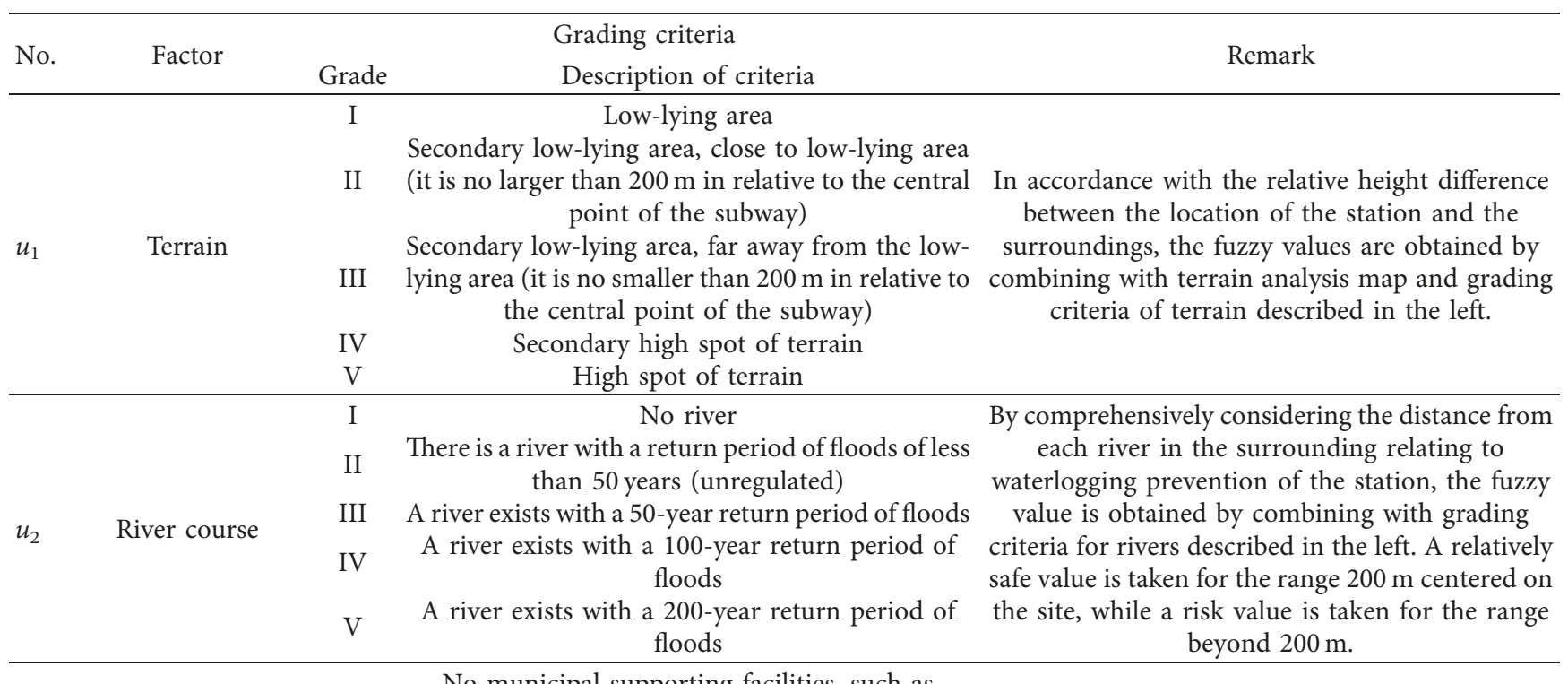

I No municipal supporting facilities, such as rainwater pipe network

Confluence system is not reformed, and the design

II working life of rainwater pipe networks is less than 0.5 years

Diversion system in old cities is used, with the By comprehensively considering various types of $u_{3}$ Rainwater facilities III design working life of rainwater pipe network of $0.5 \sim 1$ year

Diversion system is adopted, with the design working life of rainwater pipe network of $1 \sim 1.5$ years

Diversion system is adopted, with the design

$\mathrm{V}$ working life of rainwater pipe network of longer than 1.5 years

\begin{tabular}{|c|c|c|c|c|}
\hline$u_{4}$ & Feed-water pipe & III & $\begin{array}{l}\text { A main pipe for running water passes through } \\
\text { (above DN300) and it is in the foundation pit } \\
\text { A main pipe for running water passes through } \\
\text { (above DN300), and it is outside the foundation pit } \\
\text { A main pipe for running water passes through } \\
\text { (below DN300) and it is in the foundation pit. } \\
\text { A main pipe for running water passes through } \\
\text { (above DN300), and it is out of the foundation pit. } \\
\text { There is no pipe for running water }\end{array}$ & $\begin{array}{l}\text { A fuzzy value is obtained by comprehensively } \\
\text { considering the relative location of the pipe for } \\
\text { running water in the station and the adjacent } \\
\text { surrounding running water pipes (within } 50 \mathrm{~m} \text { by } \\
\text { taking the station as the center) and possible } \\
\text { movement and modification conditions. }\end{array}$ \\
\hline$u_{5}$ & Groundwater & $\begin{array}{l}\text { II } \\
\text { III } \\
\text { IV }\end{array}$ & $\begin{array}{l}\text { Groundwater is buried shallowly and has large } \\
\text { impacts } \\
\text { Groundwater is buried deeply and has slight } \\
\text { influences. }\end{array}$ & $\begin{array}{l}\text { Based on groundwater situation described in } \\
\text { geological investigation report for the station and } \\
\text { evaluation on the relationship between the station } \\
\text { and groundwater, the fuzzy value is selected in } \\
\text { grades I V. }\end{array}$ \\
\hline$u_{6}$ & $\begin{array}{l}\text { Regional } \\
\text { importance }\end{array}$ & $\begin{array}{c}\text { I } \\
\text { II } \\
\text { III } \\
\text { IV }\end{array}$ & $\begin{array}{l}\text { The score of this factor is determined subjectively by } \\
\text { environment of the station. The following three asp } \\
\text { (1) Location (central business district (CBD) area, ir } \\
\text { inside the third ring road and outside the third ring } \\
\text { the station } \\
\text { (2) Whether the station is surrounded by importar } \\
\text { government departments, financial centers, busine } \\
\text { (3) Emergency rescue conditions including road cor } \\
\text { organization, mate } \\
\text { By comprehensively considering the above thr }\end{array}$ & $\begin{array}{l}\text { py professional experts according to the surrounding } \\
\text { pects need to be comprehensively considered in the } \\
\text { ment. } \\
\text { inside the first ring road, inside the second ring road, } \\
\text { g road), pedestrian flow, and traffic conditions where } \\
\text { is located. } \\
\text { ant organizations, such as provincial and municipal } \\
\text { ess and trade areas, and cultural heritage protection } \\
\text { eas. } \\
\text { nditions, traffic conditions, power supply, personnel } \\
\text { erial allocation, etc. } \\
\text { iree aspects, grade of the factor is fuzzily rated. }\end{array}$ \\
\hline
\end{tabular}


terrain, groundwater scale, and regional importance are, the more unfavorable it is; the larger the river, rain facilities, and groundwater scale are, the more favorable the obtained results are. Therefore, the evaluation set is $V=\left\{v_{1}, v_{2}, v_{3}, v_{4}, v_{5}\right\}=\{\mathrm{I}, \mathrm{II}, \mathrm{III}, \mathrm{IV}, \mathrm{V}\}$, and specific rating grades are demonstrated in Table 5 .

3.3. Determination of Weights of Evaluation Factors. By using the AHP and entropy evaluation method, the subjective and objective weights were calculated, and the combination weight was finally obtained by utilizing the optimal combination weighting method.

3.3.1. Determining Subjective Weight Using AHP. In order to determine reasonable subjective weights, questionnaires were issued to experts in relevant fields in many provinces, including metro construction organizations, metro operation companies, metro design institutes, and professors in universities, and 15 effective questionnaires were collected. By using 1 9 scaling method, the judgment made by experts and scholars on the relative importance of the above evaluation factors is summarized. By comparing and analyzing the contributions of influence factors to waterlogging risks in the station, the judgment matrix using AHP is constructed, as shown in Tables 6 and 7. The subjective weight vectors $W_{j_{\text {subjective [operating period] }}}=(0.0903,0.0903,0.2611$, $0.0903,0.4683)$ and $W_{j_{\text {subjective[construction period] }}}=(0.1674,0.1674$, $0.0905,0.0559,0.4284,0.0905)$ in the construction and operating periods are calculated by formulas (3) and (4). Moreover, the corresponding maximum eigenvalues $\lambda_{\max [\text { construction period }]}=6.0597$ and $\lambda_{\max [\text { operating period }]}=$ 5.0040 are separately obtained. In the determination of consistency indexes, indexes of the construction period are
$\mathrm{CI}=0.0119$ and $\mathrm{CR}=0.0096<0.1$, while those in the operating period are $\mathrm{CI}=0.0010$ and $\mathrm{CR}=0.0009<0.1$. Therefore, the constructed judgment matrix is reasonable.

3.3.2. Determining Objective Weight Using Entropy Evaluation Method. Based on the calculation steps using the entropy evaluation method, the normalized judgment matrix is firstly determined and weights $W_{j_{\text {objective [operating period] }}}=(0.1477,0.3047,0.2974,0.0820,0.1680)$

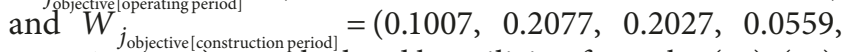
$0.3186,0.1145$ ) are calculated by utilizing formulas (13), (15), and (16).

3.3.3. Calculating Weights through Combination Weighting. By substituting the above calculated subjective and objective weights into formulas (18)-(20) of the optimal combination weighting method, the partial coefficients of the final weight of evaluation indexes for waterlogging risk in the subway station are calculated. They are $a=0.5385$ and $b=0.4615$ in the construction period as well as $a=0.6015$ and $b=0.3985$ in the operating period. Finally, by substituting them into formula (17), the combination weights $W_{\text {construction period }}=(0.1366,0.1860,0.1423,0.0559$, $0.3777,0.1016)$ and $W_{\text {operating }}$ period $=(0.1132,0.1757$, $0.2756,0.0870,0.3486)$ can be calculated.

3.4. Fuzzy Comprehensive Evaluation. According to the method for building the fuzzy evaluation model, fuzzy evaluation matrix $R$ was constructed so as to perform fuzzy evaluation and analysis on waterlogging risks in Wenjiachang Metro Depot. The fuzzy evaluation matrix $R$ is shown as follows:

$$
\begin{aligned}
& R_{\text {operating period }}=\left[\begin{array}{lllll}
0.00000 & 0.00000 & 0.84062 & 0.00000 & 0.49935 \\
0.00000 & 0.00000 & 0.14529 & 0.49935 & 0.49935 \\
0.00000 & 0.00000 & 0.00000 & 0.92574 & 0.00000 \\
0.00801 & 0.00000 & 0.00000 & 0.00000 & 0.14529 \\
0.00000 & 0.00000 & 0.92574 & 0.00000 & 0.49935
\end{array}\right] \text {, } \\
& R_{\text {construction period }}=\left[\begin{array}{lllll}
0.00000 & 0.00000 & 0.84062 & 0.00000 & 0.49935 \\
0.00000 & 0.00000 & 0.14529 & 0.49935 & 0.49935 \\
0.00000 & 0.00000 & 0.00000 & 0.92574 & 0.00000 \\
0.00801 & 0.00000 & 0.00000 & 0.00000 & 0.14529 \\
0.00000 & 0.00000 & 0.00000 & 0.00004 & 0.49935 \\
0.00000 & 0.00000 & 0.92574 & 0.00000 & 0.49935
\end{array}\right] \text {. }
\end{aligned}
$$

By calculating the fuzzy evaluation matrix $R$ by formula (26), the fuzzy evaluation vector $B$ is obtained, that is, $B_{\text {construction }}$ period $=(0.00045, \quad 0.00000,0.23590,0.22460,0.40860)$ and $B_{\text {operating period }}=(0.00070,0.00000,0.44340,0.34290,0.33100)$.
The specific corresponding relationship of fuzzy evaluation vectors and grades of membership is presented in Table 8.

Based on the maximum membership principle, the grades of waterlogging risks in Wenjiachang Metro Depot in 
TABLE 5: Grading criteria for evaluation indexes.

\begin{tabular}{|c|c|c|c|c|c|c|}
\hline Grade & Terrain & River course & Rainwater facility & Feed-water pipe & Groundwater & Regional importance \\
\hline I & 0.95 & 0.1 & 0.05 & 0.03 & 0.90 & 0.85 \\
\hline II & 0.75 & 0.2 & 0.20 & 0.15 & 0.70 & 0.70 \\
\hline III & 0.55 & 0.40 & 0.35 & 0.23 & 0.77 & 0.55 \\
\hline IV & 0.35 & 0.55 & 0.50 & 0.35 & 0.45 & 0.45 \\
\hline $\mathrm{V}$ & 0.2 & 0.70 & 0.65 & 0.45 & 0.3 & 0.3 \\
\hline
\end{tabular}

TABLE 6: Judgment matrix for influence factors in the construction period.

\begin{tabular}{lcccccc}
\hline Influence factor & $u_{1}$ & $u_{2}$ & $u_{3}$ & $u_{4}$ & $u_{5}$ & $u_{6}$ \\
\hline$u_{1}$ & 1 & 1 & 2 & 3 & $1 / 3$ & 2 \\
$u_{2}$ & 1 & 1 & 2 & 3 & $1 / 3$ & 2 \\
$u_{3}$ & $1 / 2$ & $1 / 2$ & 1 & 2 & $1 / 5$ & 1 \\
$u_{4}$ & $1 / 3$ & $1 / 3$ & $1 / 2$ & 1 & $1 / 5$ & $1 / 2$ \\
$u_{5}$ & 3 & 3 & 5 & 5 & 1 & 5 \\
$u_{6}$ & $1 / 2$ & $1 / 2$ & 1 & 2 & $1 / 5$ & 1 \\
\hline
\end{tabular}

TABLE 7: Judgment matrix for influence factors in the operating period.

\begin{tabular}{lccccc}
\hline Influence factor & $u_{1}$ & $u_{2}$ & $u_{3}$ & $u_{4}$ & $u_{6}$ \\
\hline$u_{1}$ & 1 & 1 & $1 / 3$ & 1 & $1 / 5$ \\
$u_{2}$ & 1 & 1 & $1 / 3$ & 1 & $1 / 5$ \\
$u_{3}$ & 3 & 3 & 1 & 3 & $1 / 2$ \\
$u_{4}$ & 1 & 1 & $1 / 3$ & 1 & $1 / 5$ \\
$u_{6}$ & 5 & 5 & 2 & 5 & 1 \\
\hline
\end{tabular}

TABLE 8: Corresponding relationship between fuzzy evaluation vectors and grade of membership.

\begin{tabular}{|c|c|c|c|c|c|}
\hline \multirow{2}{*}{$\begin{array}{l}\text { Evaluation vector } \\
\text { B }\end{array}$} & \multicolumn{5}{|c|}{ Membership grade } \\
\hline & I & II & III & IV & $\mathrm{V}$ \\
\hline $\begin{array}{l}\text { Construction } \\
\text { period }\end{array}$ & 0.00045 & 0.00000 & 0.23590 & 0.22460 & 0.40860 \\
\hline Operating period & 0.00070 & 0.00000 & 0.44340 & 0.34290 & 0.33100 \\
\hline
\end{tabular}

the construction period and operating period are separately $\mathrm{V}$ and III.

\section{Results and Discussion}

By utilizing the optimal combination weighting method combining subjective and objective weighting based on the AHP and entropy weight method to assign weights to evaluation factors, this study established the fuzzy synthetic evaluation model for waterlogging prevention in the construction and operating periods of the subway station in the city. Moreover, the model was applied and validated to be effective in Wenjiachang Metro Depot in phase I of Chengdu Metro Line 4, and the Wenjiachang Metro Depot showed V and III grades of flooding risks in the construction and operating periods. The evaluation results coincided with the actual situation.

In view of evaluation results, the following risk countermeasures are suggested to be used.
(1) Engineering measures:

(a) During the construction period, the combination of prevention and drainage should be adopted for safety of waterlogging prevention in the construction period in the metro depot. The measures are taken to ensure that the construction site has adequate draining and discharging capacities. For water accumulated on peripheral roads, the corresponding antiscour walls should be set according to grades of waterlogging prevention in the metro depot and temporary drainage ditches with enough water discharge capacity should be arranged in front of the antiscour walls. In the construction, special attention should be paid to protect pipes for sewage and running water in the station and its surrounding so as to prevent pipeburst accident. In addition, reliable dewatering measures should be taken to reduce groundwater level, thus eliminating threats to the foundation pit.

(b) During operating period, a policy dominated by prevention and assisted with drainage should be in line with municipal rainwater facilities in the surrounding of metro depot, and drainage standard for rainwater needs to be improved. Structures like steps in the entrances and exits of the metro depot should be high enough for ensuring safety, and flood gates should be set if necessary. Based on daily maintenance, it is necessary to increase the inspection frequency on flood gates and waterlogging prevention materials so as to ensure normal operation of equipment and allocation of waterlogging prevention materials. In the metro depot, the drainage pump station should have a certain scale to drain internal accumulated water. Furthermore, it needs to notice the treatment on nodes of pump station outlet with municipal pipe network or rivers. In terms of elevation, water sealing, and operation designs for the pump station, effective measures should be taken to ensure that external water (water from rivers and rainwater in pipes) is not poured back into the metro depot through the pump station and internal pipe network.

(2) Nonengineering treatment measures:

(a) The complete system for preventing waterlogging should be established, and special funds for flood control, disaster reduction, and flood prevention 
and waterlogging control need to be set up. In addition, social channels, such as flood control insurance should be used as much as possible to avoid disaster risks.

\section{Conclusions}

This study determined risk factors for preventing flood and draining waterlogging in the urban subways through methods, including investigation, consultation, discussion, negotiation, and reference to other literatures. In addition, the list of influence factors for risk evaluation of the urban subway was formed. These can be applied to more subway constructions, and we need to make appropriate adjustments according to the difference of each subway. We attempted to estimate weights by using the optimal combination weighting method based on the subjective AHP and objective entropy weight method. In this way, we can reduce errors between the determined weight and the possible weight of the indexes so that evaluation results are more realistic and reasonable. This method can also be applied to other research fields.

This study established the fuzzy synthetic evaluation model for waterlogging prevention in the construction and operating periods of the subway station in the city. The model was applied and validated to be effective in Wenjiachang Metro Depot in phase I of Chengdu Metro Line 4. The evaluation results coincided with the actual situation. The model in the study provides a new idea for evaluating waterlogging risks in urban subway stations, and these results can offer important information for local government to strengthen management on waterlogging risks.

We try to provide a new risk evaluation method for security experts, architecture design engineer, construction risk management engineer, government, or other relevant person, but for the constraints, this method cannot be verified comprehensively through more actual projects. Next, further research will be carried out through the whole life cycle of subway projects, not just the construction and operation periods. We hope this model is widely and practically applied, and we can achieve further research results and provide more reference for more risk assessment participants.

\section{Data Availability}

The data used to support the findings of this study are available from the corresponding author upon request.

\section{Conflicts of Interest}

The authors declare that there are no conflicts of interest regarding the publication of this paper.

\section{Acknowledgments}

This study was supported by the scientific research project funded by the Provincial Department of Education of Sichuan Province, China (18ZA0411) and the Science and
Technology Planning Project of Sichuan Province, China (2017JY0514).

\section{References}

[1] W. Pu, "Research on urban underground space flood control and countermeasures," Port and Waterway Engineering, vol. 420 , no. 10 , pp. $223-228,2008$.

[2] https://www.baidu.com/s? rtt=1\&bsst=1\&cl=2\&tn=news\&word= \%Е5\%9C\%B0\%Е9\%93\%81\%E8\%BF\%9B\%E6\%B0\%B4.

[3] S. Lou, S. Liu, G. Zhong et al., "Investigation on flood control of traffic facilities in underground spaces in Shanghai," Chinese Journal of Underground Space and Engineering, vol. 6, no. 3, pp. 611-618, 2010.

[4] W. Mo, Numerical Simulation on the Flooding in Subway Station and Discussion on its Flood Prevention Measures, Zhejiang University, Hangzhou, China, 2010.

[5] X. Wang, S. Liu, F. Su et al., "Evaluation of the effects of storm water system on the construction of the Wong Chuk Hang subway station in Hongkong subway," Water and Wastewater Engineering, vol. 36, no. 1, pp. 102-106, 2010.

[6] F. Yan, X. Wu, L. Jiang et al., "A demonstration example about underground construction influence on flood prevention in Shanghai," Chinese Journal of Underground Space and Engineering, vol. 3, no. 1, pp. 110-113, 2007.

[7] J. Zheng, "Study on countermeasure and measure of flood control of metro engineering," Urban Roads, Bridges and Flood Control, vol. 3, pp. 6-8, 2004.

[8] Z. Xiong, Y. Zhu, and Y. Zhang, "Influential factors of farmland abandonment using combination weight and SEM: from the perspective of farmer's individual capital," Economic Geography, vol. 37, no. 1, pp. 155-161, 2017.

[9] MinYang, W. Hu, and Y. Wang, "Application of optimal combined eights method and fuzzy comprehensive evaluation method in risk evaluation of the debris flow along the downstream of Zagu river," Journal of Natural Science of Heilongjiang University, vol. 34, no. 3, pp. 271-278, 2017.

[10] Q. Gu and S. Ding, "A gray evaluation method of flight safety risk based on comprehensive integration weight method," Journal of Transport Information and Safety, vol. 35, no. 6, pp. 38-45, 2017.

[11] Z. Guo, Risk Analysis and Decision, Machinery Industry Press, Beijing, China, 1987.

[12] C. Lv, F. Du, and X. Dong, "Flood control and waterlogging risk assessment of metro stations," Chinese Journal of Underground Space and Engineering, vol. 9, no. 1, pp. 190-196, 2013.

[13] F. Du, H. F. Wu, and S. Zhang, "Application of compound weight set pair modelin risk assessment of subway flood control," Water Resources and Power, vol. 36, no. 6, pp. 56-59, 2018.

[14] Y.-H. Chang and C.-H. Yeh, "A new airline safety index," Transportation Research Part B: Methodological, vol. 38, no. 4, pp. 369-383, 2004.

[15] M. Yeh, D. Osborne, D. Ross et al., "The flight operations risk assessment system," in Advances in Aviation Safety Conference and Exposition, SAE International, Warrendale, PA, USA, 1999.

[16] A. Shaygan and Ö. M. Testik, "A fuzzy AHP-based methodology for project prioritization and selection," Soft Computing, vol. 23, no. 4, pp. 1309-1319, 2019.

[17] R.-J. Kuo, Y.-H. Wu, and T.-S. Hsu, "Integration of fuzzy set theory and TOPSIS into HFMEA to improve outpatient 
service for elderly patients in Taiwan," Journal of the Chinese Medical Association, vol. 75, no. 7, pp. 341-348, 2012.

[18] A. Mehran and M. Ahmad, "A fuzzy analytic network process model to treat critical environmental risks in dams and hydropower plants," in Proceedings of the 8th International Civil Engineering Congress, Karachi, Pakistan, December 2016.

[19] Ö. M. Testik, A. Shaygan, E. Dasdemir, and G. Soydan, "Selecting health care improvement projects: a methodology integrating cause-and-effect diagram and analytical hierarchy process," Qual Manag Health Care, vol. 26, no. 1, pp. 40-48, 2017.

[20] T. L. Saaty, The Analytical Hierarchy Process, Planning, Priority. Resource Allocation, RWS Publications, Pittsburgh, PA, USA, 1980.

[21] A. Ishizaka and A. Labib, "Analytic hierarchy process and expert choice: benefits and limitations," OR Insight, vol. 22, no. 4, pp. 201-220, 2009.

[22] D. Wang, D. Shu, and C. Jiang, "The application of improved AHP methods in medium-long term load forecasting," Jilin Electric Power, vol. 38, no. 1, pp. 16-19, 2010.

[23] D. Zhou, General Systems Engineering Theory, Beijing Science Press, Beijing, China, 2007.

[24] W. Chen and D. Gong, "Informatization vendor evaluation model based on AHP entropy method," Modern Electronics Technique, vol. 35, no. 12, pp. 102-104, 2012.

[25] X. Zhao, H. Ye, and X. Deng, "Comprehensive evaluation of environmental scientific and technological capability based on the entropy method," Sichuan Environment, vol. 2013, no. 32, pp. 139-142, 2013.

[26] J. Liu, M. Fu, X. Feng et al., "application of optimal combined weights method in information security risk assessment," Journal of Chongqing University of Technology, vol. 30, no. 3, pp. 87-93, 2016.

[27] Y. Zhang, H. Li, S. Qian, Z. Li, and Z. Yue, "Study of stability gradation of highway rock slopes based on fuzzy comprehensive evaluation," Rock and Soil Mechanics, vol. 31, no. 10, pp. 3151-3156, 2010.

[28] D. Guoliang, J. Gao, and R. Li, "Risk evaluation of debris flow based on fuzzy comprehensive evaluation and entropy method," Safety and Environmental Engineering, vol. 20, no. 5, pp. 15-17, 2013. 


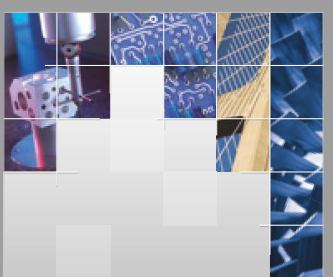

\section{Enfincering}
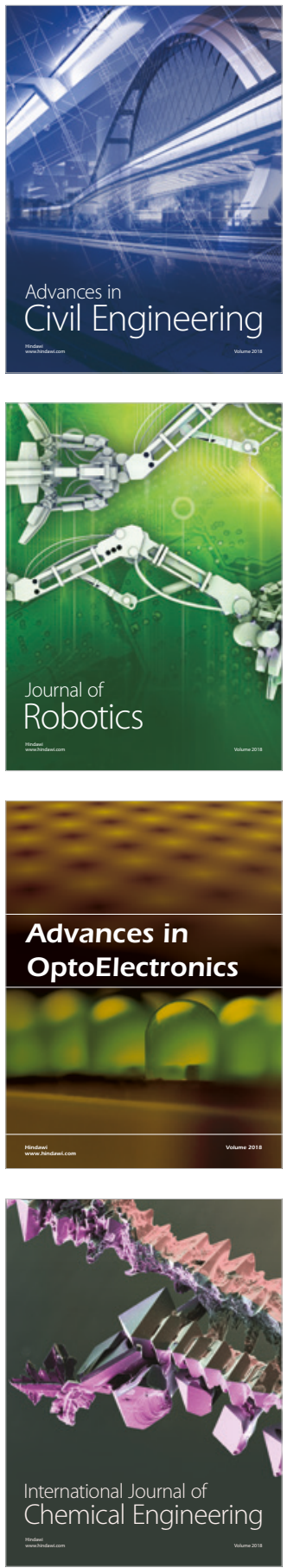

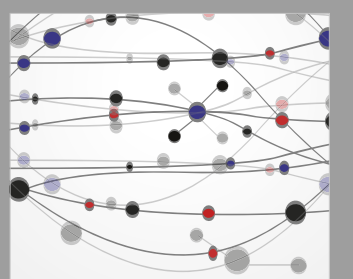

\section{Rotating \\ Machinery}

The Scientific World Journal

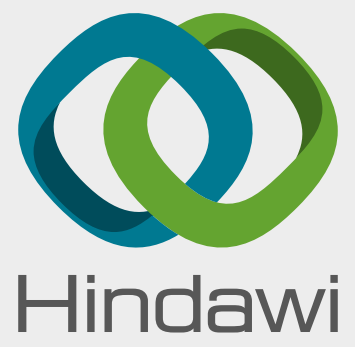

Submit your manuscripts at

www.hindawi.com
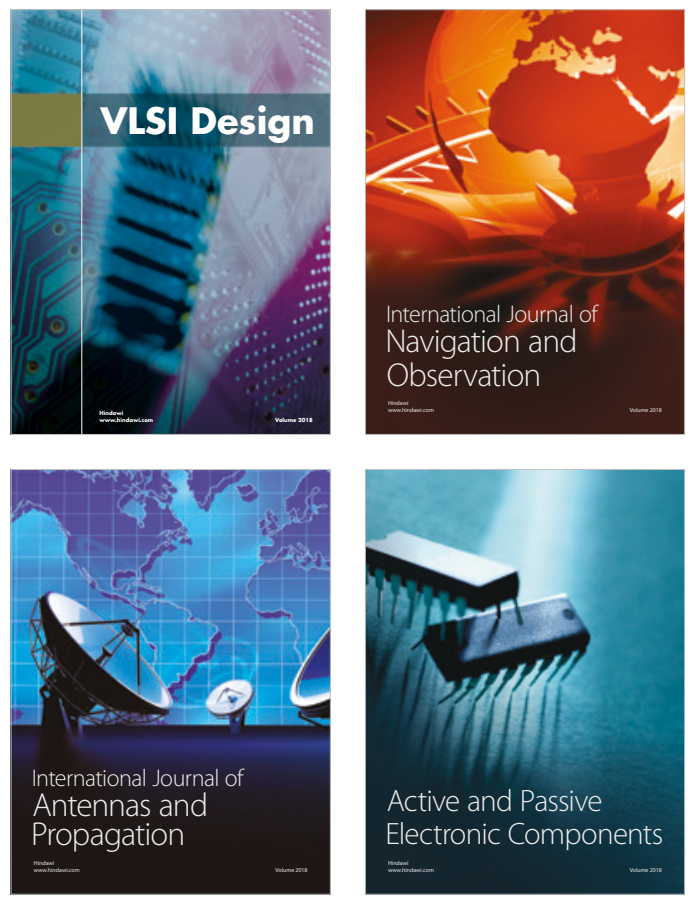
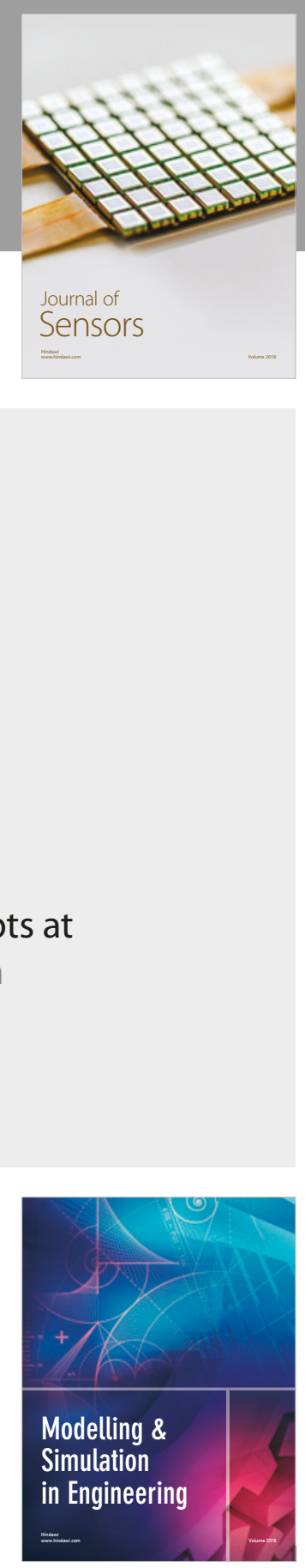

\section{Advances \\ Multimedia}
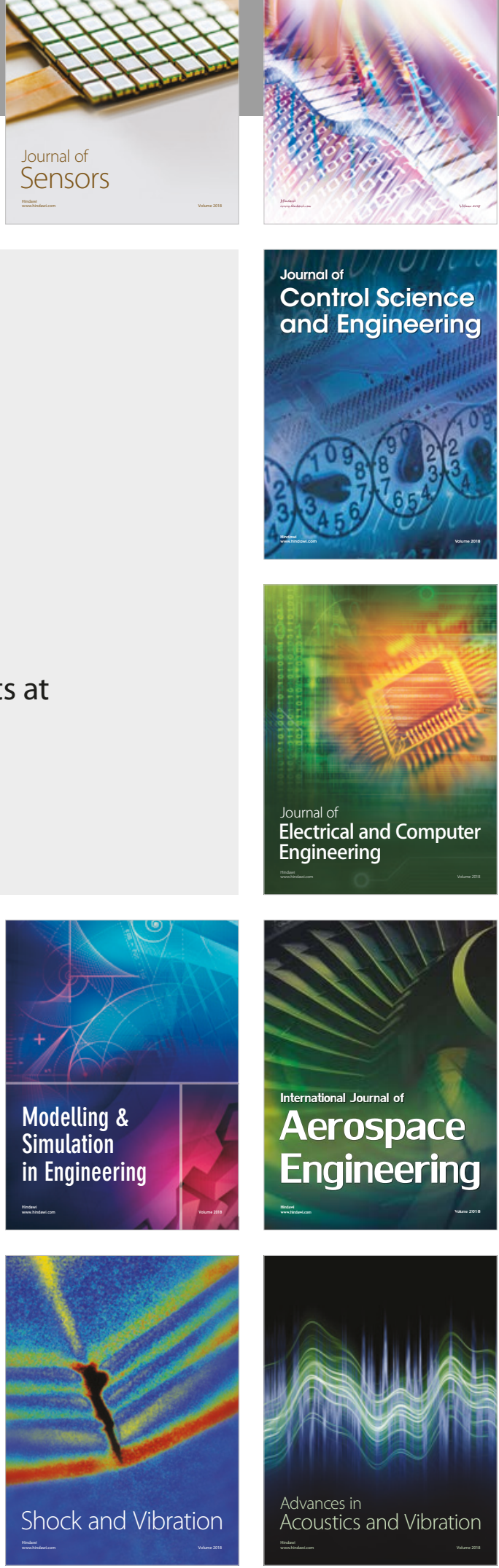